\title{
Power System Oscillations Damping by Robust Decentralized DFIG Wind Turbines
}

\author{
Tossaporn Surinkaew ${ }^{\dagger}$ and Issarachai Ngamroo*
}

\begin{abstract}
This paper proposes a new robust decentralized power oscillation dampers (POD) design of doubly-fed induction generator (DFIG) wind turbine for damping of low frequency electromechanical oscillations in an interconnected power system. The POD structure is based on the practical $2^{\text {nd }}$-order lead/lag compensator with single input. Without exact mathematical model, the inverse output multiplicative perturbation is applied to represent system uncertainties such as system parameters variation, various loading conditions etc. The parameters optimization of decentralized PODs is carried out so that the stabilizing performance and robust stability margin against system uncertainties are guaranteed. The improved firefly algorithm is applied to tune the optimal POD parameters automatically. Simulation study in two-area four-machine interconnected system shows that the proposed robust POD is much superior to the conventional POD in terms of stabilizing effect and robustness.
\end{abstract}

Keywords: Doubly-fed induction generator, Power oscillation damper, Inter-area oscillation, Robust control, Firefly algorithm.

\section{Introduction}

It is well known that the advantage of power system interconnection is the augmentation of system reliability, economics and security etc. However, the inevitable problem in longitudinal interconnected power systems is the low frequency inter-area oscillation with poor damping [1]. Under the heavy power flow condition and weak tieline, the inter-area oscillation mode may be unstable. Moreover, when the severe short circuits occur in the system, the inter-area oscillation may cause the system instability. To damp out the inter-area oscillation, the power system stabilizer (PSS) has been successfully applied [2, 3]. Nevertheless, the PSS may cause the negative impact to the voltage control of automatic voltage regulator (AVR) [4].

At present, the wind generators have been installed widely in power systems. In [5], an impact of wind power integration on generation dispatch in power systems is investigated. As sharing of wind generations increase, they should not only generate electrical power, but also contribute other functions. Especially, the damping of power system oscillation is significantly anticipated. For instance, the ability of power oscillation damping is included in the new Spanish grid code for wind power [6].

Among of wind generators, the doubly-fed induction generator (DFIG) wind turbine has been extensively used

$\dagger$ Corresponding Author: Dept. of Electrical Engineering, King Mongkut's Institute of Technology Ladkrabang, Thailand. (tsurinkaew@hotmail.com)

* Dept. of Electrical Engineering, King Mongkut's Institute of Technology Ladkrabang, Thailand. (ngamroo@hotmail.com)

Received: August 11, 2013; Accepted: October 13, 2014
[7]. Since the active and reactive power outputs of DFIG can be controlled independently by the power converters based on vector control [8], flux magnitude and angle control [9], the DFIG can be applied to stabilize the power oscillation. The power oscillation damper (POD) is equipped with the DFIG wind turbine with the same function as PSS. The PODs with various inputs such as the angle variation [4], the slip of DFIG [10] etc., have been presented and successfully damp out the power oscillation. Besides, the PODs are tuned in the small signal stability model of the power system by particle swarm optimization [11], bacterial foraging [12] and differential evolution [13] so that the dynamic performance and fault ride through capability of DFIG are improved. In power systems, however, there are various uncertainties e.g. loading conditions, wind patterns, unpredictable network, variation of system parameters and severe disturbances etc. The PODs proposed in previous works which have been designed without taking system uncertainties into account may not be able to handle the system stability. The POD with high robustness against such uncertainties is significantly required.

In [14], the robust control design of POD for DFIG has been proposed. The POD parameters optimization problem is formulated based on a mixed $H_{2} / H_{\infty}$ control using linear matrix inequalities (LMI). Simulation results in single machine infinite bus guarantee that the robustness and performance of the proposed POD is superior to the conventional POD. However, there are some limitations of the study in [14] as follows.

1) Since the objective of POD design is to stabilize the local oscillation mode in the single synchronous 
generator connected to an infinite bus, the proposed design cannot guarantee the stabilizing effect of POD on various oscillation modes such as inter-area modes, local modes etc., in a multi-machine power system. Therefore, the improvement of POD design in a multi-machine power system is highly anticipated.

2) This work considers only the single POD design which is restricted to the single-input single-output (SISO) system. To improve this, the design technique which can be applied to the multiple PODs case in the multi-input multi-output (MIMO) system, is expected.

3) A mixed $H_{2} / H_{\infty}$ control using linear matrix inequalities which is used in the POD design in this paper, has been widely applied to design power system damping controllers in the previous research works. The new design technique is significantly required.

In this paper, the new robust decentralized design of POD equipped with DFIG wind turbines for stabilization of inter-area oscillation in interconnected power systems is presented. The structure of POD is specified as a practical $2^{\text {nd }}$-order lead-lag compensator with single input. Without difficulty of mathematic representation, system uncertainties are modeled by an inverse output multiplicative perturbation. The POD parameters optimization problem is formulated so that the damping performance and robustness can be guaranteed. To achieve the optimal parameters of PODs, the firefly algorithm (FA) is used to solve the optimization problem. Simulation study conducted in a two-area four-machine power system confirms that the stabilizing effect and robustness of the proposed POD is superior to those of the conventional POD.

The organization of this paper is described as follows. First, the study system and modeling are explained in Part 2. Next, the detail of proposed design method is provided in Part 3. Subsequently, Part 4 shows simulation results. Finally, the conclusion is given.

\section{Study system and modeling}

\subsection{Study system}

Fig. 1 depicts a two-area four-machine interconnected power system [15] which is used as a study system. Each synchronous generator is represented by a $6^{\text {th }}$-order model. The synchronous generator is equipped with an AVR type 3 and a turbine governor (TG) type 2 [16]. To supply electric power to the system, the DFIG wind turbines equipped with POD are installed at bus 7 and bus 9. In this study, it is assumed that the power flow in a tie-line $\left(P_{t i e}\right)$ between bus 7 and bus 9 is in a heavy condition. Besides, system disturbances such as three phase short circuit occasionally occur in the system. These conditions cause the inter-area oscillation with poor damping. To handle this oscillation, these DFIGs equipped with PODs are applied.

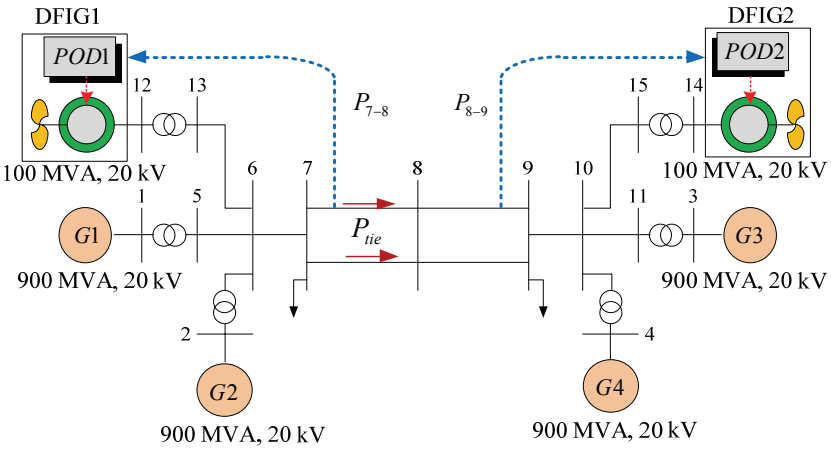

Fig. 1. Two-area four-machine system with DFIG wind turbines.

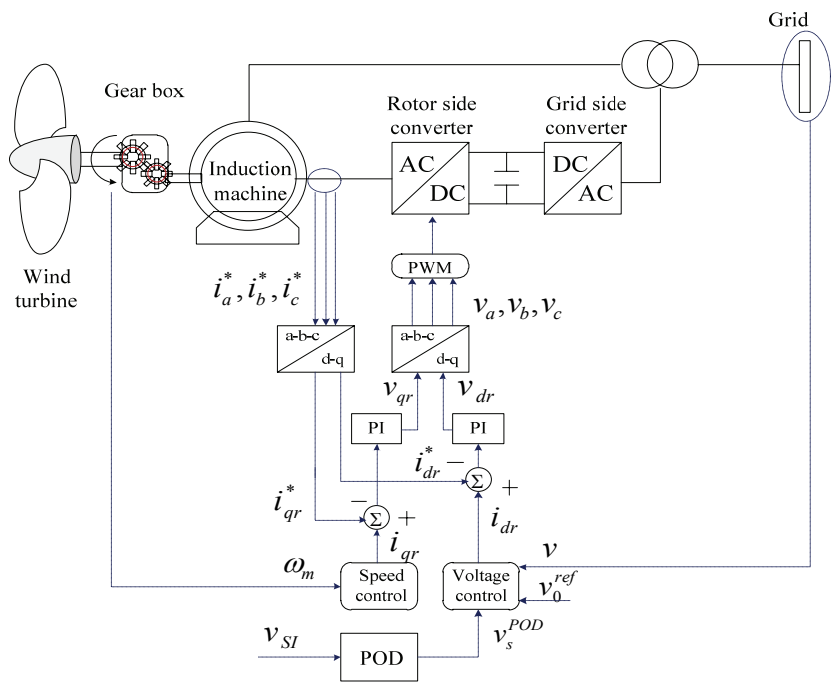

Fig. 2. Configuration of DFIG wind turbine and vector control strategy.

\subsection{DFIG model}

The structure of DFIG wind turbine and control system is demonstrated in Fig. 2 [16]. The DFIG control is performed by controlling the rotor side converter based on the vector control technique. The vector control provides an independent control of active and reactive power. Here, the flux-based rotating reference frame is used to model the DFIG. The quadrature $(q)$-axis current of the rotor side converter $\left(i_{q r}\right)$ is applied to control the real power output while the direct $(d)$-axis current $\left(i_{d r}\right)$ is used to control the reactive power output. Here, the converter is modeled as an ideal current source, where rotor currents $i_{q r}$ and $i_{d r}$ are used for rotor speed control and voltage control, respectively, which are depicted in Fig. 3(a) and 3(b). The active and reactive power of DFIG injected into the grid can be written in terms of rotor currents as

$$
\begin{aligned}
& P=\frac{x_{s}}{x_{s}+x_{u}} v i_{q r} \\
& Q=-\frac{x_{u} v i_{d r}}{x_{s}+x_{u}}-\frac{v^{2}}{x_{u}}
\end{aligned}
$$




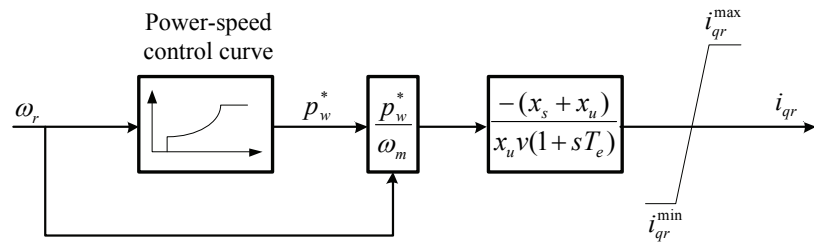

(a) Rotor speed control scheme of DFIG.

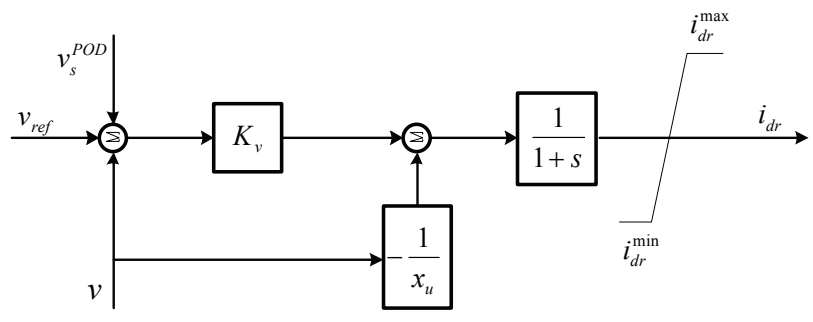

(b) Voltage control scheme of DFIG

Fig. 3. Rotor speed and voltage control scheme of DFIG.

where $P$ and $Q$ are active and reactive power of DFIG, respectively, $\omega_{m}$ is a rotor speed of DFIG, $p_{w}{ }_{w}$ is the power speed characteristic which roughly optimizes the wind energy capture, $x_{s}$ is a stator self-reactance, $x_{u}$ is a magnetizing reactance, $T_{e}$ is the time constant of power control, $v$ is a magnitude of DFIG terminal voltage, $v_{r e f}^{0}$ is the initial reference voltage, $v_{r e f}$ is the actual reference voltage, $v_{S I}$ is input signal of POD, $v_{s}^{P O D}$ is an additional signal of POD, $K_{v}$ is the voltage controller gain, and $i_{d r}$ min, $i_{d r}{ }^{\max }, i_{q r}{ }^{\min }, i_{q r}{ }^{\max }$ are $d$ and $q$ axis minimum and maximum rotor currents, respectively. Here, the stabilization of power oscillations is performed by the voltage control loop via the POD signal.

\subsection{POD model}

Fig. 4 shows the structure of the POD which is a $2^{\text {nd }}-$ order lead-lag compensator with single input. The POD consists of a stabilizer gain $K_{\text {stab }}$, a washout filter with time constant $T_{w}=5 \mathrm{~s}$, and two phase compensator blocks with time constants $T_{1}, T_{2}, T_{3}$ and $T_{4}$. The washout signal ensures that the POD output is zero in steady state. The input signal $v_{S I}$ is the active power flow in the representative transmission line where the inter-area oscillation mode can be observed easily. Here, the input signals of POD1 and POD2 are the power flow in line 7-8 and line 8-9, respectively. The output signal $v_{s}^{P O D}$ is subject to an anti-windup limiter, $v_{s}{ }^{\min }$ and $v_{s}^{\max }$ are minimum and maximum of $v_{s}^{P O D}$. The gain $K_{\text {stab }}$ determines the amount of damping produced by POD while the phase compensator

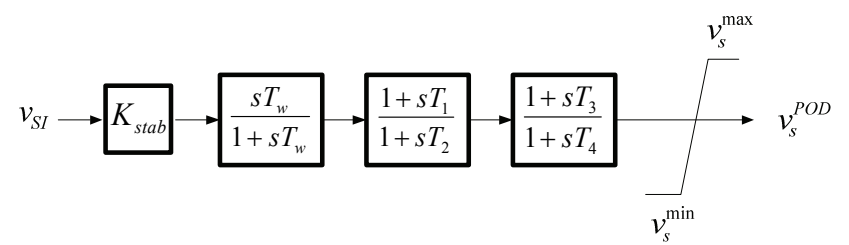

Fig. 4. Structure of POD. block gives the appropriate lead-lag compensation of the output signal.

\subsection{Linearized power system model}

The linearized system state equations in Fig. 1 can be expressed by

$$
\begin{aligned}
& \dot{x}=A_{(n \times n)} \Delta x+B_{(n \times m)} \Delta u_{P O D} \\
& \Delta y=C_{(m \times n)} \Delta x+D_{(m \times m)} \Delta u_{P O D}
\end{aligned}
$$

where $\Delta x$ is a state vector $\left[\Delta \delta \Delta \omega \Delta e_{q} \Delta e_{d} \Delta e^{\prime \prime} \Delta e^{\prime \prime}{ }_{d} \Delta v_{m}\right.$ $\left.\Delta v_{r} \Delta v_{f} \Delta x_{g} \Delta v_{w} \Delta \omega_{m} \Delta \theta_{p} \Delta i_{d r} \Delta i_{q r}\right], \Delta \delta$ is a power angle deviation, $\Delta \omega$ is a rotor speed deviation, $\Delta e_{q}^{\prime}$ is a $q$-axis transient internal voltage deviation, $\Delta e_{d}^{\prime}$ is a $d$-axis transient internal voltage deviation, $\Delta e_{q}$ is a $q$-axis sub transient internal voltage, $\Delta e_{d}{ }_{d}$ is a $d$-axis sub transient internal voltage deviation, $\Delta v_{m}$ is a measurement voltage deviation, $\Delta v_{r}$ is a regulator voltage deviation, $\Delta v_{f}$ is a field voltage deviation, $\Delta x_{g}$ is an output signal of governor deviation, $\Delta v_{w}$ is an output signal of wind speed deviation, $\Delta \omega_{m}$ is a rotor speed deviation of DFIG, $\Delta \theta_{p}$ is a pitch angle deviation, $\Delta i_{d r}$ is a DFIG rotor current deviation in $d$-axis, $\Delta i_{q r}$ is a DFIG rotor current deviation in $q$-axis, $\Delta u_{P O D}$ is an input vector of POD signal, $\Delta y$ is an output vector of power flow in tie-line deviation, $n$ is a number of state variables, $m$ is a number of PODs, $A$ is a system matrix, $B$ is an input matrix, $C$ is an output matrix and $D$ is a feed forward matrix.

The output vector $\triangle u_{P O D}$ consists of the $m^{\text {th }}$ control signal from POD $\left(\Delta u_{P O D, m}\right)$ which can be expressed by

$$
\Delta u_{P O D, m}=K_{s t a b, m} \frac{s T_{w}}{1+s T_{w}} \frac{1+s T_{m 1}}{1+s T_{m 2}} \frac{1+s T_{m 3}}{1+s T_{m 4}} \Delta P_{t i e, m}
$$

where $\Delta P_{\text {tie, } m}$ is a tie-line power deviation of the $m^{\text {th }}$ POD, $K_{s t a b, m}, T_{m 1}, T_{m 2}, T_{m 3}$ and $T_{m 4}$ are gain and time constants of the $m^{\text {th }}$ POD. These gain and time constants are optimally

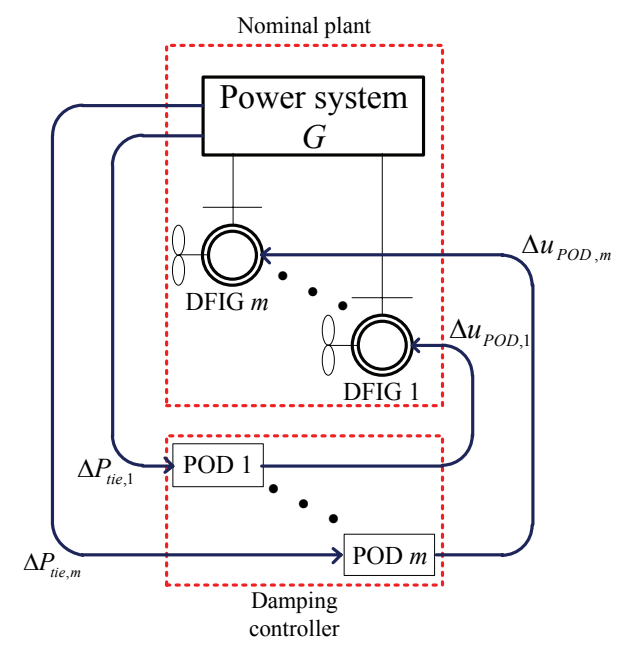

Fig. 5. MIMO system $G$ with a decentralized controller $K$. 
tuned by the proposed design. Note that the system in (2) is the multi-input multi-output (MIMO) control system and referred to as the nominal plant $G$. The multi-machine power system included with PODs can be represented by an MIMO system $G$ with a decentralized controller $K$, as depicted in Fig. 5. An MIMO system $G$ is composed of $m$ inputs and $m$ outputs while a controller $K$ consists of $m$ PODs as diagonal controllers.

\section{Proposed robust design controller}

\subsection{Uncertainty modeling}

Robustness is a vital issue in control system design because real systems are vulnerable to system uncertainties. To improve the robustness of POD against system uncertainties such as various generating and loading conditions, wind patterns, and unpredictable network structure etc., the inverse output multiplicative perturbation is applied to represent such uncertainties without difficulty of exact equations. Fig. 6 depicts the feedback control system with inverse output multiplicative perturbation and external disturbance [17] where, $G$ is the nominal plant, $K$ is the designed controller, $r(t)$ is the reference input, $e(t)$ is the error tracking, $d(t)$ is the external disturbance, $y(t)$ is the output of the system and $\Delta_{M}$ is the system uncertainties. Based on the small gain theorem [17], for a stable multiplicative uncertainty, the system stable if

$$
\left\|\Delta_{M}(I+G K)^{-1}\right\|_{\infty}<1
$$

Then,

$$
\left\|\Delta_{M}\right\|_{\infty}<1 /\left\|(I+G K)^{-1}\right\|_{\infty}
$$

Define the robust stability index $\left(\gamma_{\infty}\right)$ as

$$
\gamma_{\infty}=\left\|(I+G K)^{-1}\right\|_{\infty}
$$

As a result

$$
\left\|\Delta_{M}\right\|_{\infty}<1 / \gamma_{\infty}
$$

In (7), the value of $\left\|\Delta_{M}\right\|_{\infty}$ implies the maximum

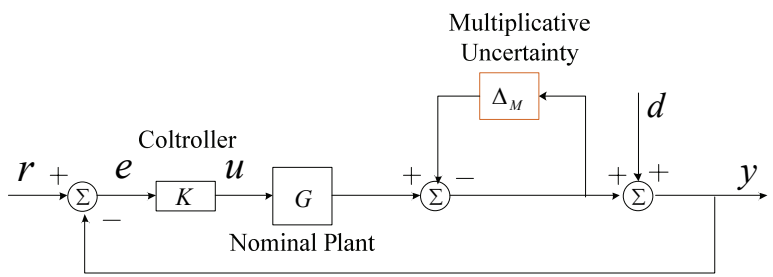

Fig. 6. Control system with inverse output multiplicative perturbation and external disturbance.

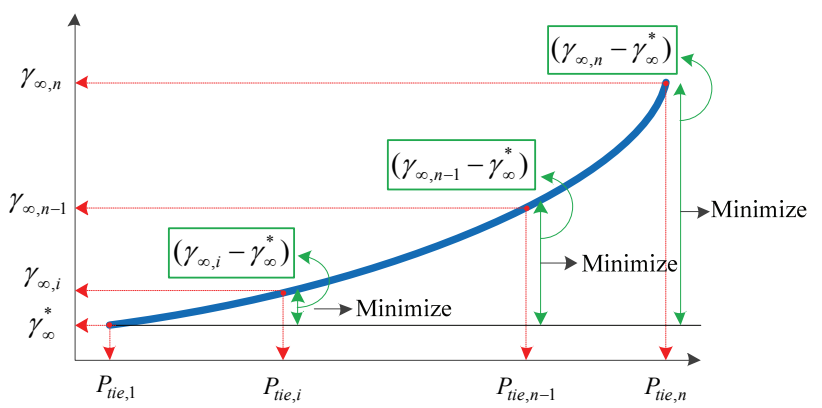

Fig. 7. Relation between $\gamma_{\infty}$ and $P_{\text {tie }}$.

boundary of uncertainties that the system can tolerate. When $\gamma_{\infty}$ increases, this boundary decreases, and the system robust stability margin becomes lower. In power systems, $P_{t i e}$ is the system variable which highly affects the system robust stability [18]. When $P_{\text {tie }}$ increases, $\gamma_{\infty}$ tends to increase (lower robust stability margin). In this study, it is assumed that $P_{\text {tie }}$ increases with the same amount. Fig. 7 shows the relation between $P_{t i e}$ with respect to $\gamma_{\infty}$. Note that $P_{t i e, i}$, and $\gamma_{\infty, i}, i=1, . ., n$, are the $i^{\text {th }}$ data of tie line power flow and the $i^{\text {th }}$ data of $\gamma_{\infty}$, respectively, and $n$ is the number of power flow data. The $P_{t i e, n}$ which is the $n^{\text {th }}$ data of $P_{t i e}$ can be written in the form of the arithmetic sequence as

$$
P_{t i e, n}=P_{t i e, 1}+(n-1) d_{a s}
$$

where $d_{a s}$ is a difference value between $P_{t i e, i}$ and $P_{t i e, i-1}$, $i=1, \ldots n$. It should be noted that $d_{a s}$ is a constant value.

The $\gamma_{\infty, i}$ which corresponds to $P_{t i e, i}$, is calculated by

$$
\gamma_{\infty, i}=\left\|\left(I+G_{i} K\right)^{-1}\right\|_{\infty}
$$

where $G_{i}$ is the $i^{\text {th }}$ data of the nominal plant $G$ at $P_{\text {tie, } i}$

In Fig. 7, $\gamma_{\infty}^{*}$ which is the minimal value of $\gamma_{\infty, i}$, implies the highest robust stability margin of the system against uncertainties. When the sum of difference between $\gamma_{\infty, i}$ and $\gamma_{\infty}^{*}$ is minimized, $\gamma_{\infty, i}$ is nearly equal to $\gamma_{\infty}^{*}$. It means that the proposed controller can provide the system robust stability margin at any $P_{t i e, i}$.

In addition, the controller is designed to move the eigenvalue corresponding to all oscillation modes to the Dstability region with the desired real part $\left(\sigma_{\text {spec }}\right)$ and the

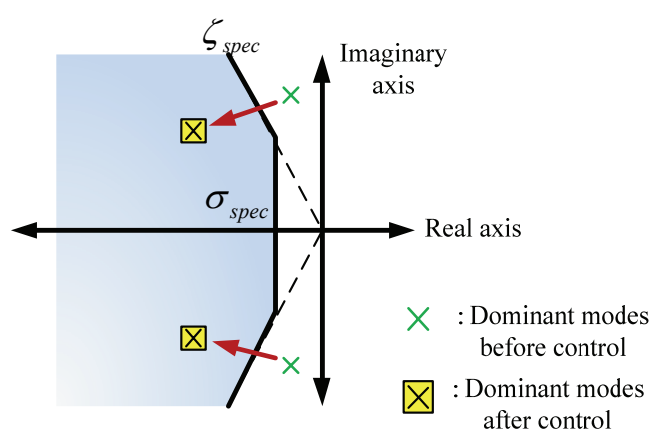

Fig. 8. D-stability region. 
desired damping ratio $\left(\zeta_{\text {spec }}\right)$ of eigenvalue as depicted in Fig. 8.

Based on the above concept, the parameters optimization problem of PODs can be written as

$$
\begin{aligned}
\text { Minimize } & R F \sum_{i=1}^{n}\left(\gamma_{\infty, i}-\gamma_{\infty}^{*}\right) \\
\text { Subject to } & \zeta_{h} \geq \zeta_{s p e c}, \sigma_{h} \leq \sigma_{\text {spec }}, h=1, \ldots, \text { os } \\
& \gamma_{\infty}^{*} \leq \gamma_{\infty, \text { spec }}^{*} \\
& K_{\text {stab }}^{\min }<K_{\text {stab }, m}<K_{\text {stab }}^{\max } \\
& T^{\min }<T_{m, j}<T^{\max }, m=1,2 \text { and } j=1, \ldots, 4 .
\end{aligned}
$$

where $\zeta_{h}$ is the damping ratio of the $h^{\text {th }}$-oscillation mode, $\sigma_{h}$ is the real part of the $h^{\text {th }}$-oscillation mode, os is the number of all oscillation modes, $\gamma_{\infty, \text { spec }}^{*}$ is the specified value of $\gamma_{\infty}{ }^{*}$, which is appropriately selected by the designer, $R F$ is the ranking factor, $K_{\text {stab }}{ }^{\min }$ and $K_{\text {stab }}{ }^{\max }$ are minimum and maximum gains, $T^{\mathrm{min}}$ and $T^{\mathrm{max}}$ are minimum and maximum time constraints.

Note that, the damping ratios and real parts of all oscillation modes in an area or between two areas can be improved so that they satisfy with the design specification.

\subsection{Firefly algorithm applied for the optimization problem}

The FA is a meta-heuristic algorithm inspired by the flashing behavior of fireflies [19]. The primary purpose of a firefly's flash is to act as a signal system to attract other fireflies. For this work, the firefly algorithm is applied to solve the objective function (10) with parameters of POD i.e. $K_{s t a b, m}$ and $T_{m, j}, m=1,2$ and $j=1, \ldots, 4$. Consequently, the step-by-step of the improved firefly algorithm is readjusted as the following.

1. Generate initial population of each firefly with random positions and light intensity.

2. For each firefly, if $\zeta_{h} \geq \zeta_{\text {spec }}, \sigma_{h} \leq \sigma_{\text {spec }}, h=1, \ldots, o s$ and $\gamma_{\infty}{ }^{*}$ $\leq \gamma^{*}{ }_{\infty, \text { spec }}$ go to step 3. Otherwise go to step 1 .

3. Check the number of firefly, if number of firefly $=$ number of max firefly, then go to step 4. Otherwise go to step 1 .

4. Evaluate the objective function in (10) by using $R F$ as follows;

$$
R F=1-\text { error }
$$

where

$$
\text { error }=\left(\gamma_{\infty, \text { spec }}^{*}-\gamma_{\infty}^{*}\right) / \gamma_{\infty, \text { spec }}^{*}
$$

In (11), the $R F$ is used to determine the value of (10). The error implies the difference between $\gamma_{\infty, \text { spec }}^{*}$ and $\gamma_{\infty}{ }^{*}$. 5. Rank the fireflies by their light intensity, i.e. the value of objective function.

6. Move all fireflies towards brighter ones $x_{a+1}$ by

$$
x_{a+1}=x_{a} \beta_{0} e^{-\gamma_{a b}^{2}}\left(x_{b}-x_{a}\right)+\alpha(\text { rand }-0.5)
$$

where $\alpha$ is the randomization parameter, rand is the random number in $(0,1), \beta_{0}$ is the attractiveness at $r=0, r$ is the distance between any fireflies $i$ and $j$ at $x_{a}$ and $x_{b}, \gamma$ is the light absorption coefficient.

$$
r_{a b}=\sqrt{\sum_{z=1}^{d}\left(x_{a, z}-x_{b, z}\right)^{2}}
$$

where $d$ is the number of tuned parameters, $z=1, \ldots, d$.

According to the objective function (10), the values of $x_{a}$ and $x_{b}$ which consists of the tuned parameters of the PODs, are presented by

$$
\begin{aligned}
& x_{a}=\left[\begin{array}{ll}
K_{s t a b, m, a} & T_{j, a}
\end{array}\right]^{T} \\
& x_{b}=\left[\begin{array}{ll}
K_{s t a b, m, b} & T_{j, b}
\end{array}\right]^{T}, m=1,2, j=1, \ldots, 4
\end{aligned}
$$

where the subscript $a$ and $b$ are tuned parameters at position $x_{a}$ and $x_{b}$, respectively, $x_{a, z}$ and $x_{b, z}$ are

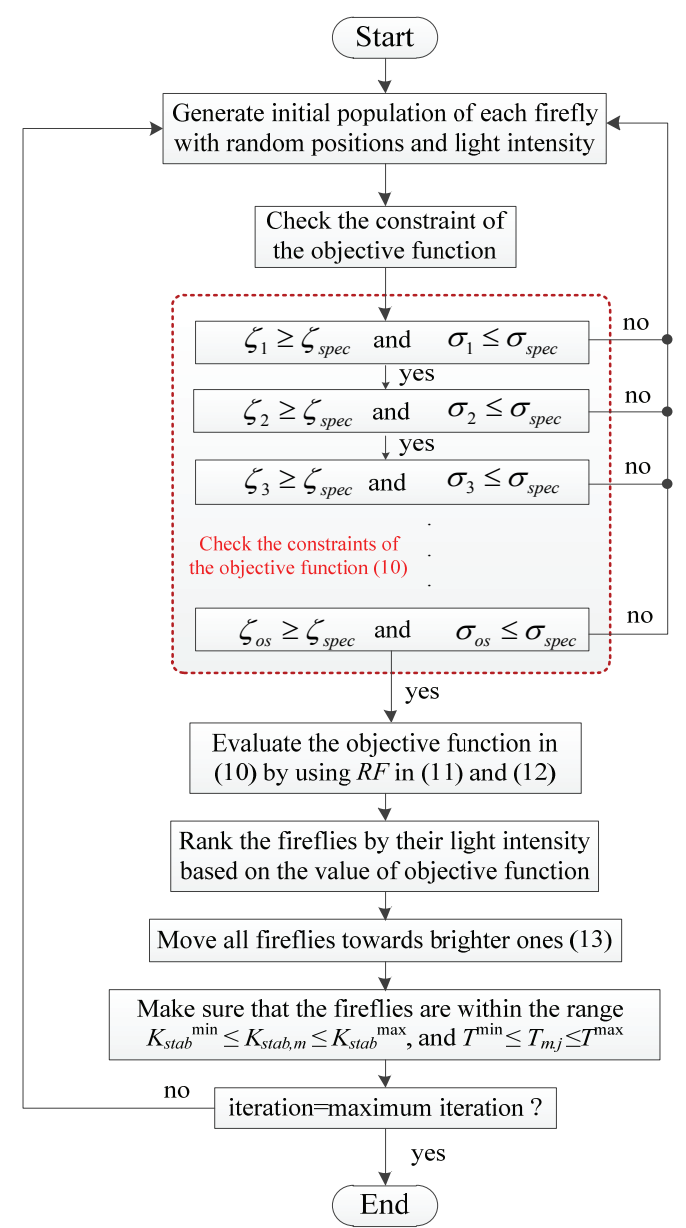

Fig. 9. Flow chart of improved firefly algorithm. 
parameters of PODs which corresponding to the $z$ series data of $x_{a}$ and $x_{b}$, respectively. Note that, when the firefly moves from the current position $x_{a}$ to the new position $x_{a+1}$ by substituting (15) into (13) and (14), this results in the change in parameters of PODs. Accordingly, the value of objective function in (10) is updated.

7. Make sure that the fireflies are within the range,

$$
K_{\text {stab }}^{\min } \leq K_{\text {stab }, m} \leq K_{\text {stab }}{ }^{\max } \text {, and } T^{\min } \leq T_{m, j} \leq T^{\max } .
$$

8. When the maximum number of is reached, stop the process. Otherwise, go to step 4.

The flow chart of improved firefly algorithm for solving the optimization problem (10) is depicted in Fig. 9.

\section{Simulation results}

In the simulation study, MATLAB programming and Power System Analysis Toolbox (PSAT) [20] are used. The parameters of FA and search parameters are set as follow; number of firefly $=30$, maximum iteration $=350, \alpha=0.2, \gamma=1$, $\beta_{0}=1, \zeta_{\text {spec }}=0.05$ (or 5\%), $\sigma_{\text {spec }}=-0.1, P_{\text {tie }, 1}=2.0$ p.u., $d_{a s}=0.3$, $\gamma_{\infty, s p e c}^{*}=1.5, \quad o s=3$ (two local modes and one interareamode), $\left[K_{\text {stab }}{ }^{\min } K_{\text {stab }}{ }^{\max }\right]=[0.115]$, and $\left[T^{\min } T^{\mathrm{max}}\right]=[0.1$ $10]$.

Fig. 10 depicts the convergence of the objective function (10) in case of the proposed robust POD which is referred to as "DFIG-RPOD". The DFIG-RPOD is compared with the conventional POD designed without considering the robustness which is stand for "DFIG-CPOD". Based on the pole assignment method, the DFIG-CPOD is designed at $P_{\text {tie }}=4.0$ p.u. to yield the same damping ratio and real part of the dominant modes as in case of DFIG-RPOD. The optimization problem of DFIG-CPOD is formulated as follows;

Minimize $\sum_{\zeta \leq \zeta_{\text {spec }}}\left|\zeta-\zeta_{\text {spec }}\right|+\sum_{\sigma \geq \sigma_{\text {spec }}}\left|\sigma-\sigma_{\text {spec }}\right|$

Subject to $\zeta \geq \zeta_{\text {spec }}, \sigma \leq \sigma_{\text {spec }}$

$$
\begin{aligned}
& K_{s t a b}^{\min }<K_{s t a b, m}<K_{s t a b}^{\max } \\
& T^{\min }<T_{m, j}<T^{\max }, m=1,2 \text { and } j=1, \ldots, 4 .
\end{aligned}
$$

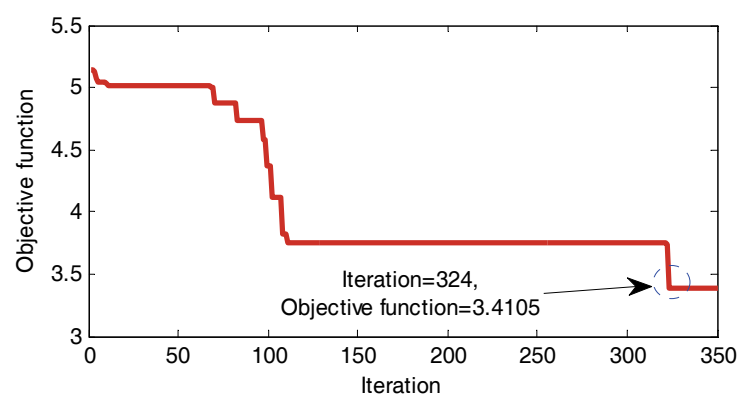

Fig. 10. Convergence curve of the objective function (10).
Table 1. Optimized parameters of DFIG-CPOD and DFIGRPOD.

\begin{tabular}{c|c|c|c|c|c}
\hline Controller & $K_{\text {stab }}$ & $T_{1}$ & $T_{2}$ & $T_{3}$ & $T_{4}$ \\
\hline \multicolumn{6}{c}{ DFIG-CPOD } \\
\hline POD1 & 10.2645 & 1.2895 & 0.5785 & 1.0257 & 1.0954 \\
\hline POD2 & 7.2132 & 4.1127 & 7.9984 & 4.4123 & 0.7864 \\
\hline \multicolumn{6}{c}{ DFIG-RPOD } \\
\hline POD1 & 9.2664 & 3.5858 & 0.1275 & 1.2835 & 0.2315 \\
\hline POD2 & 8.9132 & 5.2994 & 6.1816 & 2.7104 & 0.2124 \\
\hline
\end{tabular}

Table 2. Eigenvalue analysis result

\begin{tabular}{c|c|c|c|c}
\hline \multirow{2}{*}{$\begin{array}{c}\text { Type of } \\
\text { controller }\end{array}$} & \multicolumn{2}{|c|}{ Eigenvalue } & $\begin{array}{c}\text { Damping } \\
\text { ratio (\%) }\end{array}$ & $\begin{array}{c}\text { Frequency } \\
(\mathrm{Hz})\end{array}$ \\
\hline \multirow{2}{*}{$\begin{array}{c}\text { Without } \\
\text { POD }\end{array}$} & Local1 & $-0.76 \pm 6.96 i$ & 10.86 & 1.11 \\
\cline { 2 - 5 } & Local2 & $-0.69 \pm 7.18 i$ & 9.58 & 1.14 \\
\cline { 2 - 5 } & Inter-area & $-0.11 \pm 4.13 i$ & 2.54 & 0.66 \\
\hline \multirow{2}{*}{$\begin{array}{c}\text { DFIG- } \\
\text { CPOD }\end{array}$} & Local1 & $-1.14 \pm 6.99 i$ & 16.00 & 1.11 \\
\cline { 2 - 5 } & Local2 & $-1.13 \pm 7.22 i$ & 15.40 & 1.15 \\
\cline { 2 - 5 } & Inter-area & $-0.62 \pm 4.07 i$ & 14.99 & 0.65 \\
\hline \multirow{2}{*}{$\begin{array}{c}\text { DFIG- } \\
\text { RPOD }\end{array}$} & Local1 & $-1.09 \pm 6.89 i$ & 15.63 & 1.09 \\
\cline { 2 - 5 } & Local2 & $-1.04 \pm 7.21 i$ & 14.28 & 1.15 \\
\cline { 2 - 5 } & Inter-area & $-0.60 \pm 4.1 i$ & 14.58 & 0.65 \\
\hline
\end{tabular}

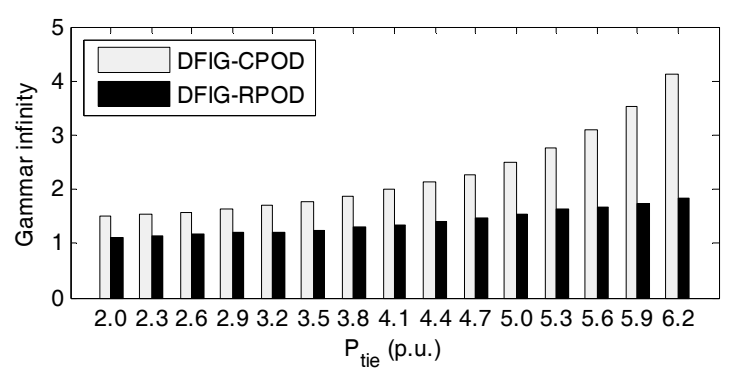

Fig. 11. The variation of $\gamma_{\infty}$ against an increase in $P_{\text {tie }}$.

The optimization objective in (16) is to move the dominant oscillation to the D-stability region as show in Fig. 8. Solving (10) and (16) by FA, the optimized parameters of DFIG-CPOD and DFIG-RPOD are given in Table 1.

Table 2 provides the eigenvalue and damping ratio of the dominant inter-area oscillation mode. The damping ratio of oscillation mode is very poor in case of without POD. On the other hand, the damping ratio is improved as designed specification by both DFIG-CPOD and DFIG-RPOD.

The robustness of DFIG-CPOD and DFIG-RPOD is evaluated by $\gamma_{\infty}$. Fig. 11 depicts the variation of $\gamma_{\infty}$ against an increase in $P_{\text {tie }}$. Obviously, $\gamma_{\infty}$ is case of DFIG-CPOD largely changes. The DFIG-CPOD is very sensitive to the uncertainty due to the tie-line power flow. On the other hand, $\gamma_{\infty}$ is case of DFIG-RPOD rarely changes. The DFIGRPOD is not sensitive to variation of the tie-line power flow.

Next, the variation of damping ratio against an increase in $P_{\text {tie }}$ is depicted in Fig. 12. Under heavy power flow condition, the damping ratio in case of DFIG-CPOD largely decreases. On the other hand, the damping ratio in case of DFIG-RPOD is still greater than $5 \%$ of the desired damping ratio.

The nonlinear simulation of four case studies as given in Table 3 is carried out by PSAT. The uncertainty handing 


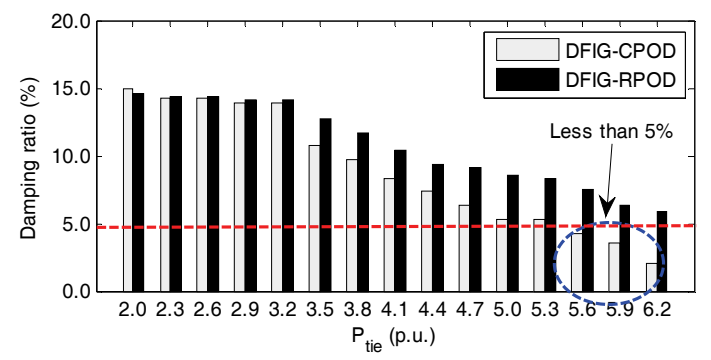

Fig. 12. The variation of damping ratio against an increase in $P_{\text {tie }}$.

Table 3 Case studies (base 100 MVA).

\begin{tabular}{|c|c|c|c|c|}
\hline \multirow{3}{*}{ Case } & \multirow{3}{*}{$\begin{array}{c}P_{\text {tie }} \\
\text { (p.u.) }\end{array}$} & \multicolumn{3}{|c|}{ Uncertainties handing information } \\
\hline & & \multirow[t]{2}{*}{ Applied disturbance } & \multicolumn{2}{|c|}{$\begin{array}{l}\text { Wind patterns } \\
\text { applied to each } \\
\text { DFIG }\end{array}$} \\
\hline & & & DFIG1 & DFIG2 \\
\hline 1 & 4.0 & $\begin{array}{l}\text { A } 3 \text { phase fault occurs at one line } \\
\text { between bus } 8 \text { and bus } 9 \text { at } t=1.0 \mathrm{~s} \text {, the } \\
\text { fault is cleared by opening the circuit } \\
\text { breaker at line between bus } 8 \text { and bus } 9 \\
\text { at } t=1.05 \mathrm{~s} \text { and not reclosed. }\end{array}$ & $\begin{array}{l}\text { Fig.13 } \\
\text { (a)-1 }\end{array}$ & $\begin{array}{r}\text { Fig.13 } \\
\text { (a) }-2\end{array}$ \\
\hline 2 & 5.0 & Same case 1 . & $\begin{array}{c}\text { Fig.13 } \\
\text { (b) }-1\end{array}$ & $\begin{array}{l}\text { Fig.13 } \\
\text { (b)-2 }\end{array}$ \\
\hline 3 & 5.2 & $\begin{array}{l}\text { A temporary } 3 \text { phase fault occurs at bus } \\
7 \text { at } t=1.0 \mathrm{~s} \text { for } 65 \mathrm{~ms} \text {, the fault is } \\
\text { cleared naturally. }\end{array}$ & $\begin{array}{l}\text { Fig.13 } \\
\text { (c)-1 }\end{array}$ & $\begin{array}{l}\text { Fig. } 13 \\
\text { (c) }-2\end{array}$ \\
\hline 4 & 5.6 & $\begin{array}{l}\text { A } 3 \text { phase fault occurs at one line } \\
\text { between bus } 7 \text { and bus } 8 \text { at } t=1.0 \mathrm{~s} \text {, the } \\
\text { fault is cleared by opening the circuit } \\
\text { breaker at line between bus } 7 \text { and bus } 8 \\
\text { at } t=1.08 \mathrm{~s} \text { and not reclosed. }\end{array}$ & $\begin{array}{l}\text { Fig.13 } \\
\text { (d)-1 }\end{array}$ & $\begin{array}{c}\text { Fig.13 } \\
\text { (d) }-2\end{array}$ \\
\hline
\end{tabular}
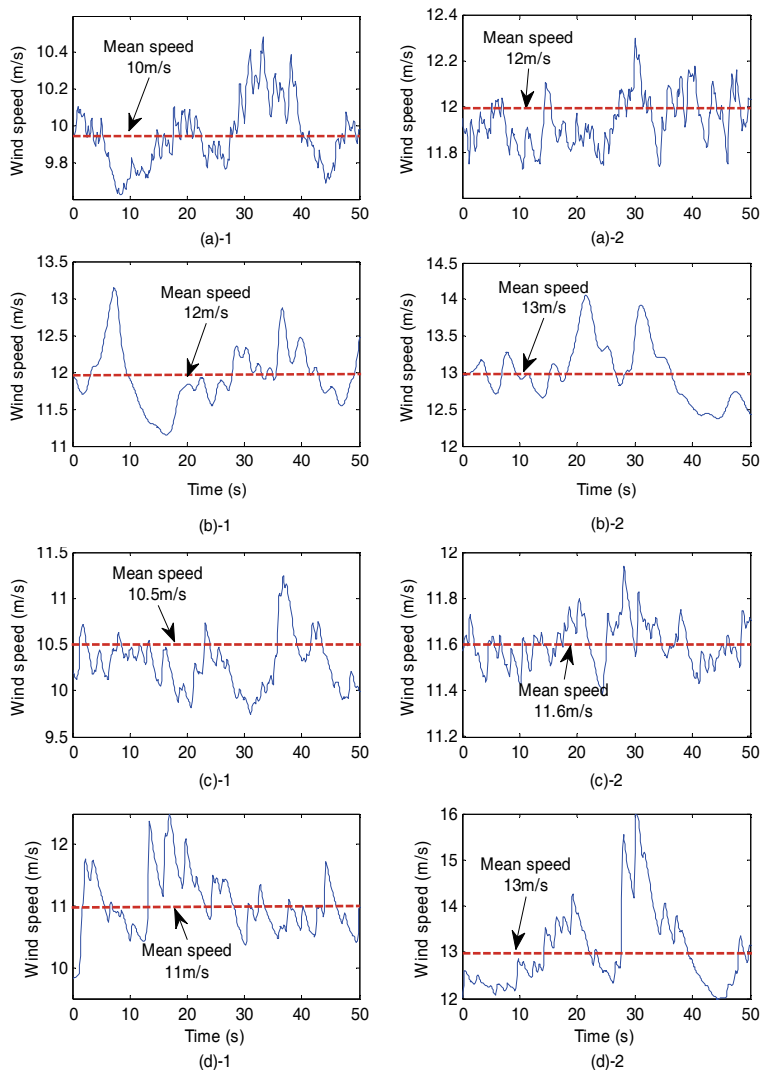

Fig. 13. Patterns of wind. information given in Table 3 consists of three items as follows;

1. Uncertainty due to the wind patterns applied to both DFIGs as shown in Fig. 13.

2. Uncertainty due to the variation power flow levels in tieline between bus 7 and bus 9 .

3. Uncertainty due to the applied faults and network structure after fault clearing.

Figs. 14-17 depict the rotor speeds of four synchronous generators. In case 1 as shown in Fig. 14, without POD the rotor speeds largely oscillate. On the other hand, the oscillations are effectively damped by both DFIG-CPOD and DFIG-RPOD. In case 2 as depicted in Fig. 15, the damping effect of DFIG-CPOD is much less than that of DFIG-RPOD. In cases 3 and 4 as shown in Figs.16 and 17, respectively, the stabilizing effect of DFIG-CPOD is completely deteriorated. The rotor speeds severely oscillate and the synchronous generators lose synchronism. On the
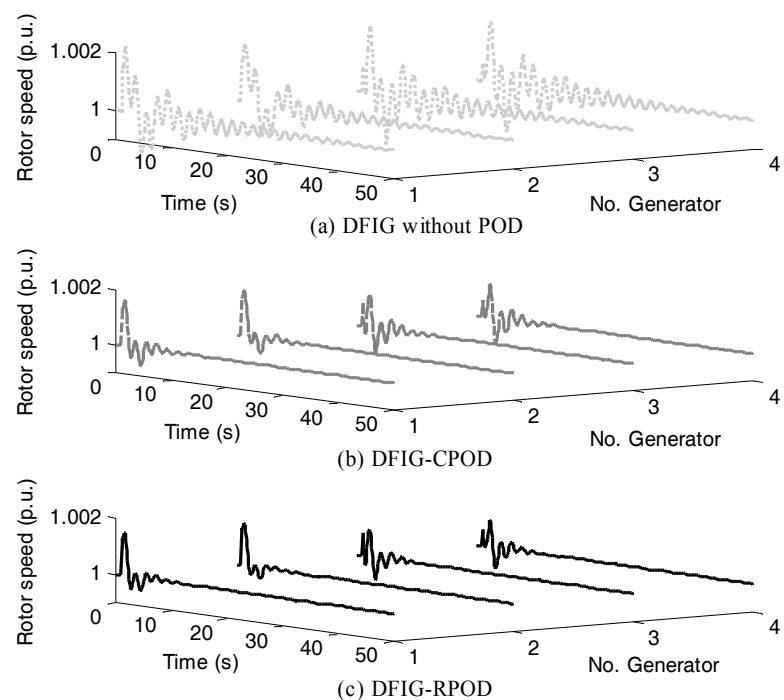

Fig. 14. Rotor speeds of synchronous generators in case 1 .

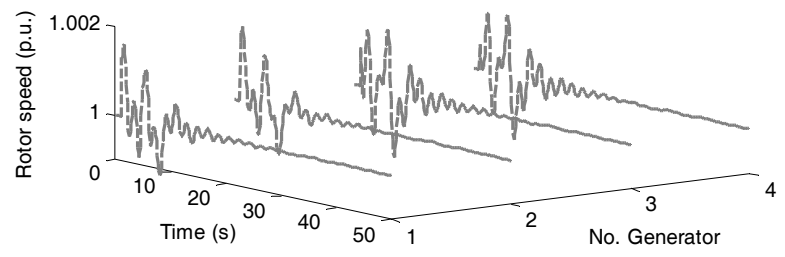

(a) DFIG-CPOD

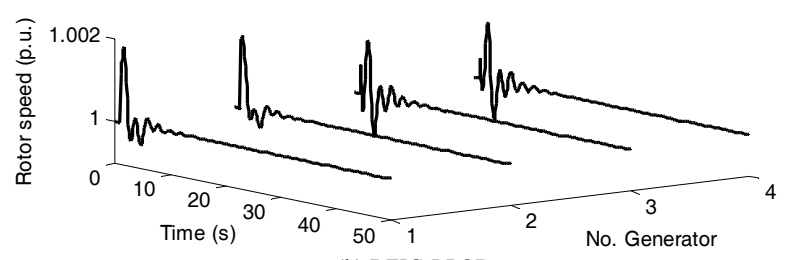

(b) DFIG-RPOD

Fig. 15. Rotor speeds of synchronous generators in case 2 . 

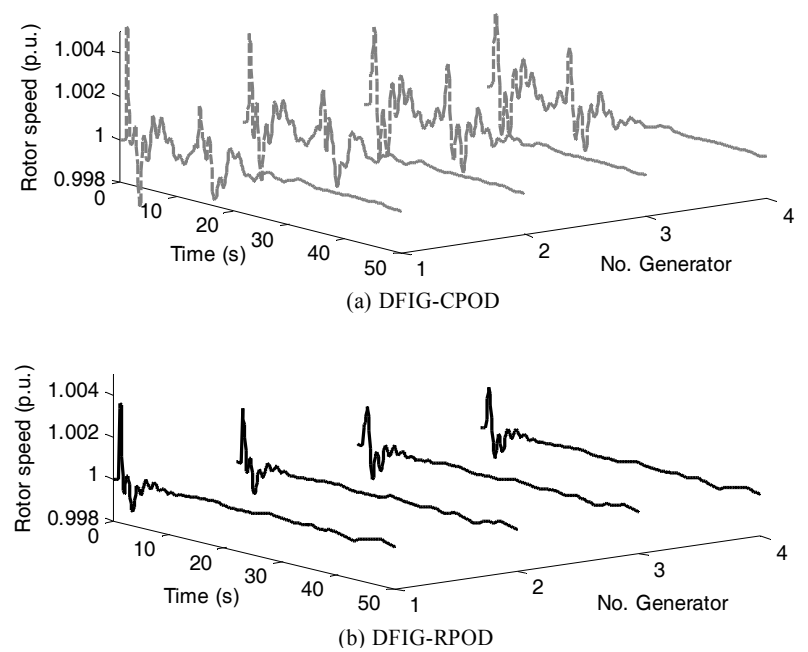

Fig. 16. Rotor speeds of synchronous generators in case 3.
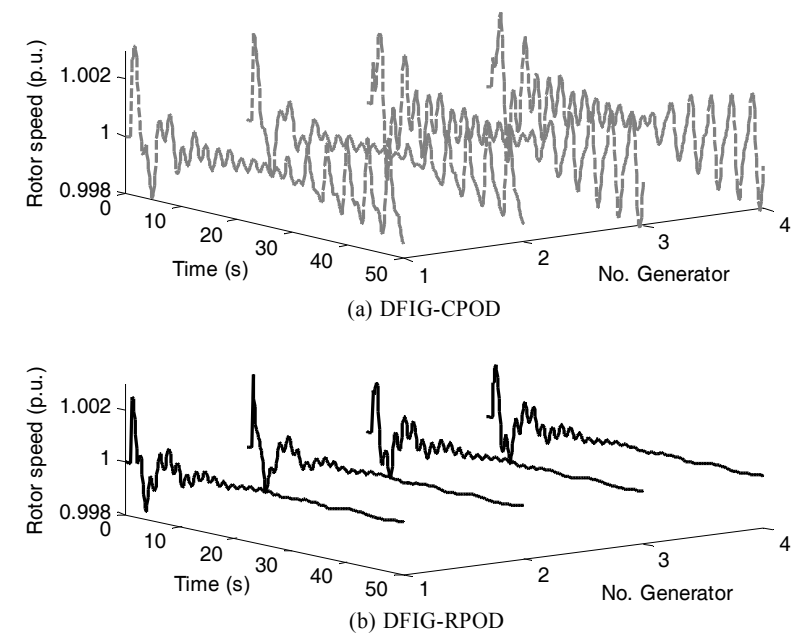

Fig. 17. Rotor speeds of synchronous generators in case 4 .

other hand, the DFIG-RPOD is robustly capable of damping out the oscillation. Simulation results confirm that the DFIG-RPOD is very robust against the various power flow levels, wind patterns and severe faults.

\section{Conclusion}

In this paper, the new robust decentralized controller design of PODs equipped with DFIG wind turbines has been presented. Without exact mathematical equation, the inverse output multiplicative perturbation model is adopted to represent system uncertainties. The POD structure is the practical $2^{\text {nd }}$-order lead/lag compensator with single input. The parameters of PODs are simultaneously and automatically optimized by FA so that the robust stability margin and damping effect are improved. Simulation study confirms that the robustness and stabilizing performance of the proposed robust POD is much superior to those of the conventional POD under various faults, wind patterns and heavy tie-line power flow conditions.

\section{Acknowledgements}

This work was supported by the King Mongkut's Institute of Technology Ladkrabang Research Fund no. KREF 055706 .

\section{References}

[1] AR. Messina "Inter-area oscillations in power systems: a nonlinear and nonstationary perspective," Springer, 2009.

[2] J. Machowski, J. W. Bailek, J. R. Bumby. "Power system dynamics stability and control," $2^{\text {nd }}$ edition, Wiley, 2008.

[3] W. Yao, L. Jiang, J. Fang, J. Wen, S. Wang, "Damping of Inter-Area Low Frequency Oscillation Using an Adaptive Wide-Area Damping Controller," J Electr Eng T echnol, vol.9, no. 1, pp. 27-36, 2014.

[4] F. Hughes, O. Anaya-Lara, N. Jenkins, G. Strbag. "Control of DFIG-based wind generation for power network support," IEEE Trans. on Power Systems, no. 4, vol. 20, pp. 1958-66, Nov. 2005.

[5] J.-K. Lyu, J.-H. Heo, M.-K. Kim, J.-K. Park, "Impacts of Wind Power Integration on Generation Dispatch in Power Systems," J Electr Eng T echnol, vol. 8, no. 3, pp. 453-463, 2013.

[6] D. G. José Luis, G. B. Oriol, D. B. Fernando, S. Andreas "Power oscillation damping supported by wind power: a review", Renewable and Sustainable Energy Reviews, vol. 16, pp.4982-93, Sept. 2012.

[7] H.T. Jadhav, R. Roy "A comprehensive review on the grid integration of doubly fed induction generator", Int J Elect Power Energy Syst, vol.49, pp.8-18. July 2013.

[8] J.L. Dominguez-Garcia, O. Gomis-Bellmunt, L. TrillaRomero, Junyent-Ferre A. "Vector control of squirrel cage induction generator for wind power", Proc Int Conf Electrical Machines, 2010.

[9] C. Jauch, T. Cronin, P. Sorensen, B.Jensen "A fuzzy logic pitch angle controller for power system stabilization", Wind Energy, vol. 10, pp. 19-30, 2007.

[10] O. Anaya-Lara, F. Hughes, N. Jenkins, G. Strbag "Power system stabilizer for a generic DFIG-based wind turbine controller", Proc $8^{\text {th }}$ IEE Int Conf AC DC Power Trans, pp. 145-149, 2006.

[11] F. Wu, Z. Zhang, K. Godfrey, P. Ju "Small signal stability analysis and optimal control of a wind turbine with doubly fed induction generator", IET Gener Transm Distrib, no. 5, vol. 1, pp. 751-60, 2007.

[12] Y. Misha, S. Mishar, M. Triphathy, N. Senroy, Z. Y. Dong, "Improving stability of a DFIG-based wind power system with tuned damping controller", IEEE Trans on Energy Convers, no. 3, vol. 24, pp. 650-60, Sept. 2009.

[13] L. Yang, G. Y. Yang, Z. Xu, Z. Y. Dong, K. P. Wong, 
X. Ma "Optimal controller design of a doubly-fed induction generator with wind turbine system for small signal stability enhancement". IET Gener Transm Distrb, no. 5, vol.4, pp.579-97, 2010.

[14] T. Surinkaew, I. Ngamroo, and W. Nakawiro, "Robust Power Oscillation Damper Design for DFIG-based Wind Turbine", in Proc. $10^{\text {th }}$ International Conference on ECTI-CON, 2013.

[15] P. Kundur "Power system stability and control", McGrawhill, 1994.

[16] F. Milano "Power system modelling and scripting", Springer, 2010.

[17] S. Skoqestad, Postlethwaite I. "Multiple feedback control: analysis and design", Wiley, 2005.

[18] B.Chaudhuri, B.C. Pal, A.C. Zolotas, I.M. Jaimoukha, and T.C. Green, "Mixed-sensitivity approach to $\mathrm{H}_{\infty}$ control of power system oscillations employing multiple FACTS devices," IEEE Trans. on Power Syst., vol. 18, no. 3, pp. 1149-1156, Aug. 2003.

[19] X.S. Yang. "Engineering optimization: an introduction with metaheuristic applications", Wiley, 2010.

[20] F. Milano "Power system analysis toolbox version 2.1.6”, 2011.

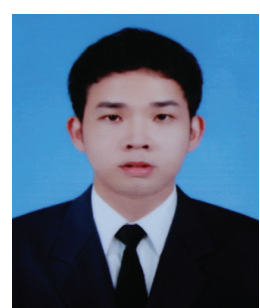

stability.

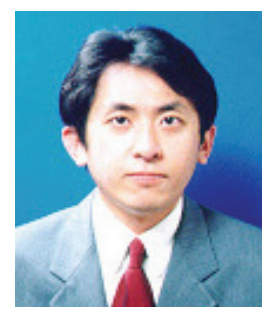

Issarachai Ngamroo received B.Eng. degree in Electrical Engineering from KMITL in 1992. He earned his M.Eng. and Ph.D. degrees in Electrical Engineering from Osaka University, Japan in 1997 and 2000, respectively. Currently, he is a professor of electrical engineering department, faculty of engineering, KMITL. His research interests are in the areas of power system stability, dynamics \& control. 